\title{
URANIUM REMOVAL FROM AQUEOUS SOLUTION USING TRI-N-BUTYL PHOSPHATE AND DI-2-ETHYLHEXYL PHOSPHORIC ACID FUNCTIONALIZED POLYESTER SHEET AND CHARCOAL AS ADSORBENTS
}

\author{
Shabaan S. M. ${ }^{1}$, Daher A. M. ${ }^{2}$, Hussein A. E. M. ${ }^{2}$, Abdel Aal M. M. ${ }^{2}$, Hosni A. G. ${ }^{1}$ \\ And Awais M. S. ${ }^{2}$ \\ ${ }^{1}$ Alazhar University, Faculty of science (boys), Cairo, Egypt. \\ ${ }^{2}$ Nuclear Material Authority, Box 530, Maadi-Kattameya, Cairo, Egypt. \\ Corresponding author: Hosni Anwar, Hosniag@ Alazhar.edu.eg \\ Phone 00201126879760 \\ Chemistry department, Faculty of science, Al-Azhar University, Cairo, Egypt.
}

\section{1- ABSTRACT}

The present investigation deals with the removal of uranium from a nitric acid waste solution (Raffinate solution: produce during yellow cake of uranium production) using the extraction chromatography technique (solvent impregnated material)), where Tri-N-butyl phosphate (TBP) and Di-2-ethylhexyl phosphoric acid (D2EHPA) solvents were impregnated upon polyester sheet and charcoal respectively then the impregnated resin were tested for uranium removal. Thus, the factors affecting the impregnation process namely, solvent concentration, impregnation time, volume/mass ratio, impregnation temperature and diluents type were studied. Secondly the influences of initial uranium concentration, adsorption temperature, contact time, $\mathrm{pH}$ on the uranium adsorption on the prepared materials were studied. From the results the isotherm models also calculated to determine uranium adsorption behavior by the prepared TBP and D2EHPA impregnated polyester sheet and charcoal respectively. Both prepared materials were found to be fitted with Langmuir than Freundlich model isotherm.

Keywords: Uranium, Removal, D2EHPA, TBP, Impregnation, Adsorption, Elution

\section{2- INTRODUCTION}

Uranium as a key element in nuclear fuel cycle is abundant in aquifers around mining, processing and milling sites, posing a potential environment and health risk to the biosphere due to its radioactivity and toxicity [1-3]. Many methods were used for treating the high concentration radioactive wastewater such as chemical precipitation, ion-exchange, extraction and reverse osmosis process [4-7]. These methods are so cost when they are used to treat the low concentration radioactive wastewater [8, 9]. Liquid-liquid extraction usually used an aqueous phase and an organic phase containing extractants [10-12], and the key point is the extractants $[13,14]$. Some alternative methods with similar principles of solvent extraction have been developed for metal partitioning and extraction, such as solid phase extraction (SPE) and ion-exchange chromatography (IEC) [15-17]. Solid-liquid extraction more beneficial in view of their total insolubility of the applied solid in the aqueous phase, its low rate of physical degradation besides, its high sorption capacity as well as its good flexibility and kinetic properties [18, 19]. Uranium nitrate in solution is usually present as cationic species. Consequently it could be selectively separated by ion exchange resins containing cation exchange functional groups. Ion exchange technique is low-cost, highly effective, efficient and easy to operate among the treatment processes. Ion exchange materials are widely used for the hydrometallurgical uranium recovery from acid leach mineral ore bodies [20].

In the present work uranium from nitric acid solution the solid phase extraction by 
impregnate TBP and D2EHPA upon polyester and charcoal respectively has been done. Thus, the factors affecting the impregnation process namely, solvent concentration, impregnation time, volume/mass ratio, impregnation temperature and diluents type were studied. Then the effects of initial uranium concentration, adsorption temperature, contact time, $\mathrm{pH}$ of uranium adsorption on the prepared materials were studied. From the results the isotherm models also calculated to determine uranium adsorption behavior by the prepared TBP and D2EHPA impregnated polyester and charcoal respectively. Abstract finally, the optimum conditions were applied on waste solution sample.

\section{3- EXPERIMENTAL}

\subsection{Materials and analytical procedure:}

The liquid waste experimental sample (raffinate solution) used in this study was collected from Nuclear Materials Authority, Egypt its average chemical composition is shown in Table (1). All reagents used were of

Table (1): Chemical composition of the working raffinate waste sample

\begin{tabular}{|c|c|}
\hline Constituent & Concentration \\
\hline $\mathrm{Fe}_{2} \mathrm{O}_{3}$ & $0.60 \mathrm{~g} / \mathrm{L}$ \\
$\mathrm{HNO}_{3}$ & $1 \mathrm{M}$ \\
$\mathrm{U}(\mathrm{VI})$ & $100 \mathrm{mg} / \mathrm{L}$ \\
$\mathrm{Ca}(\mathrm{II})$ & $1.9 \mathrm{~g} / \mathrm{L}$ \\
\hline
\end{tabular}

Analytical reagent grade. $\mathrm{D}_{2} \mathrm{EHPA}$, TBP, Uranyl nitrate were supplied from RiedeldeHaen. Synthetic solutions of the uranyl nitrate were prepared by dissolving the exact amount of uranyl nitrate in distilled water. Uranium concentration was determination spectrophotometrically by UV single beam model SP-8001", Metretech Inc., version 1.02 using Arsenazo III method [21] at pH 2 [22] and by an oxidimetric titration against ammonium metavanadate method using $\mathrm{N}$ phenyl anthranilic acid indicator (SigmaAldrich) [23, 24].
3.2. Preparation of adsorbent materials solvent (Impregnation procedure)

\subsubsection{Preparation of the inert materials}

The polyester sheet and charcoal macro porous were immersed in $2 \mathrm{M} \mathrm{HCl}$ for $1 \mathrm{~h}$, washed with distilled water until free of $\mathrm{HCl}$, and air-dried overnight before using. The polyester sheet of $0.5 \mathrm{~cm}$ in diameter and 0.50 $\mathrm{cm}$ length (average weight $=0.05 \mathrm{~g}$ ), was cut from a polyester sheet.

\subsubsection{Impregnation procedure}

To investigate the influences affecting impregnation process, series of impregnation experiments have been performed by shaking $0.25 \mathrm{~g}$ of the dry clean polyester sheet and charcoal samples with the properly prepared impregnation solutions of Tri-N-butyl phosphate (TBP) and Di-2-ethylhexyl phosphoric acid (D2EHPA) solvents (in benzene) solution by magnetic stirrers. The amount of solvent impregnated on the polyester sheet and charcoal samples were calculated by the difference between the weight before and after the process as the following equation. The studied factors included solvent concentration, impregnation temperature, impregnation time, mass/volume ratio and diluents type.After the end of the impregnation experiments, the foam is dried in the oven for $1 \mathrm{~h}$ at a temperature of $60^{\circ} \mathrm{C}$ to evaporate the diluent (leaving the diffused solvent into the materials pores).

$$
\text { Mass Change, } \%=100 \times \frac{m 2-m 1}{m 1}
$$

Where $m_{1}$ and $m_{2}$ are the dry polyester sheet and charcoal mass before and after impregnation process respectively.

\subsection{Sorption Studies}

\subsubsection{Sorption Procedure}

The behavior of uranium (VI) adsorption onto the prepared adsorbent materials was carried out by using batch sorption experiments via shaking $0.05 \mathrm{~g}$ of impregnated materials with $10 \mathrm{mLof}$ the uranium and synthetic solutions $160 \mathrm{mg} / \mathrm{L}$ each individually. The studied relevant adsorption factors are: effect of 
contact time, initial uranium concentrations, $\mathrm{pH}$ and solution temperature. The adsorbed amounts of uranium were calculated by difference between the equilibrium and initial concentrations. The amount of ion retained in the solid phase qe $(\mathrm{mg} / \mathrm{g})$ was calculated using the relation:

$$
q e, m g / g=(\mathrm{Co}-\mathrm{Ce}) \times \frac{V}{M}
$$

Where $C_{0}$ and $C_{e}$ are the initial and equilibrium concentrations of the metal in the aqueous phase in $\mathrm{mol} / \mathrm{L}$, respectively, $\mathrm{V}$ gives the volume of the aqueous phase solution in $\mathrm{mL}$ and $m$ is the weighed dry impregnated resin in g. Where the uptake percent of the metal ion by the impregnated materials was calculated according to the following relation:

$$
\text { Uptake, } \%=100 \times(\mathrm{Co}-\mathrm{Ce}) \times \mathrm{Co}
$$

\subsubsection{Equilibration Calculation}

All uranium speciation in this study were performed with Hydra-MEDUSA, a chemical equilibrium calculation program $[25,26]$.

\section{RESULT AND DISCUSSION}

\subsection{Results of the relevant impregnation process factors}

\subsubsection{Effect of solvent concentration}

To determine the effect of TBP and D2EPHA concentration upon the impregnation results, several impregnation experiments were carried out using fixed conditions at temperature $25^{\circ} \mathrm{C}$, time of $1 \mathrm{~h}$., v/m ratio is $5 \mathrm{~g}$ $/ \mathrm{L}$ and diluents is benzene. Different TBP and D2EPHA concentration is ranging from 0.028 up to $0.50 \mathrm{M}$. From the Fig (1) the impregnation by solvent increased as the solvent concentration increased reach to maximum at $0.45 \mathrm{M}$ concentration. Behind the later concentration the saturation of polymer and charcoal by solvent was reached. In other words the surface of the inert support was covered by solvent. Accordingly, $0.45 \mathrm{M}$ is the preferred condition for further impregnation experiments for TBP or D2EPHA upon polyester sheet and charcoal.

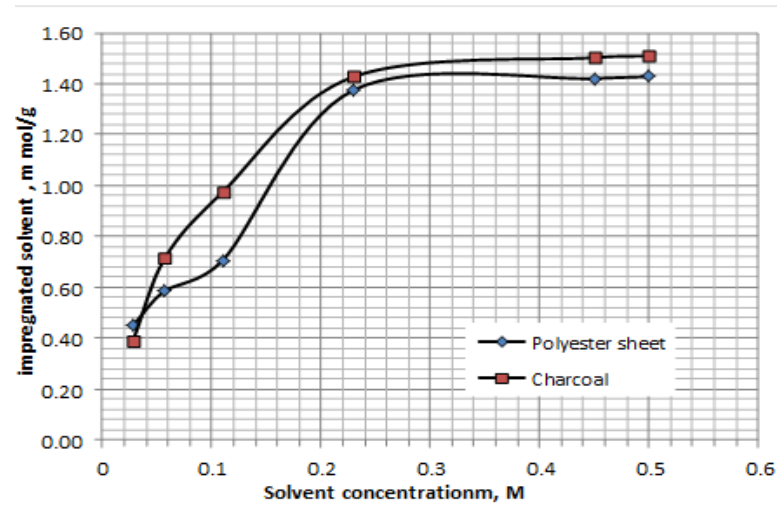

Fig. (1): Effect of solvents (TBP and D2EPHA) concentration upon the impregnated amount onto the dry polyester sheet and charcoal $\left(\mathrm{T}: 25^{\circ} \mathrm{C}\right.$, time: $1 \mathrm{~h}$., ratio: $5 / 1$ and Diluents: benzene. Conc.: $0.028-0.5 \mathrm{M}$ or Molar).

\subsubsection{Shaking Time Effect}

To determine the effect of impregnation time or shaking time upon the impregnated solvent amount upon polyester sheet and charcoal, several impregnation experiments were carried out using fixed conditions of temperature $25{ }^{\circ} \mathrm{C}$, solvents concentration of $0.45 \mathrm{M}, \mathrm{v} / \mathrm{m}$ ratio of $5 / 1$ and benzene as diluent. Shaking time is ranging from 0.5 to 24 hours. From the Fig (2) the impregnated by solvent amount is gradually increased form the first experiment to the fourth one of $5 \mathrm{~h}$. After $5 \mathrm{~h}$ of shaking time no investigated increase in the impregnated solvent amount. Consequently, 5h is sufficient time to fill of all the surface porous for both polyester sheet and charcoal and the surface are completely coated with solvents under these conditions.

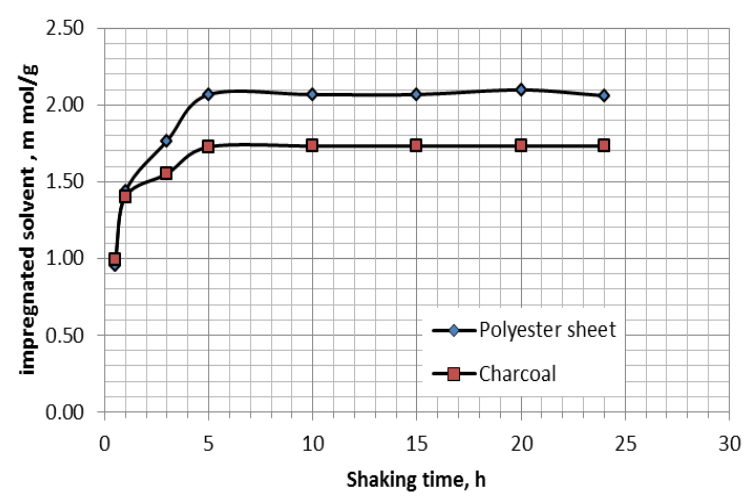

Fig. (2): Effect of shaking time upon the loaded amounts of TPB and D2EHPA onto polyester sheet and charcoal (T: $25^{\circ} \mathrm{C}$, time: 0.5 to 24 h., ratio: $5 / 1$ and Diluents: benzene. Conc.: 0.45 Molar). 


\subsubsection{Effect of mass/volume ratio}

To study the effect of $\mathrm{m} / \mathrm{v}$ ratio upon the amounts of TBP and D2EHPA impregnated onto the working polyester sheet and charcoal samples, two series of impregnation experiments were performed using $\mathrm{m} / \mathrm{v}$ ratios started from $1 / 1$ up to $1 / 10$. These experiments were performed under fixed conditions of $25^{\circ} \mathrm{C}$ impregnation temperature, $5 \mathrm{~h}$ impregnation time, $0.5 \mathrm{M}$ solvent concentrations and using benzene as diluent. The obtained results are plotted in Fig. 3. From this figure the amount of loaded solvent onto the polyester sheet and charcoal increased with increasing the impregnation solution $\mathrm{m} / \mathrm{v}$ ratio. After $\mathrm{m} / \mathrm{v}$ of 5 $\mathrm{g} / \mathrm{L}$ the impregnated amount were approximately fixed. From the mentioned above $5 \mathrm{~g} / \mathrm{L} \mathrm{m} / \mathrm{v}$ ratio were the preferred for both polyester sheet and charcoal.

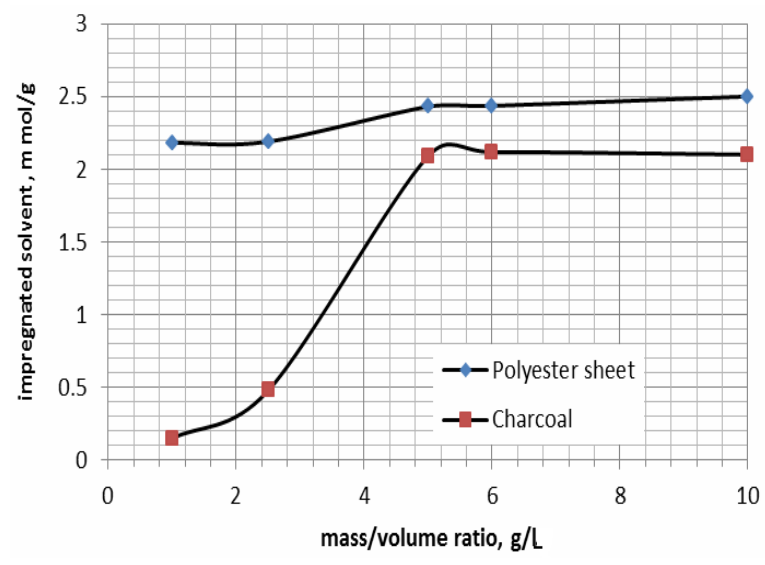

Fig. (3): Effect of impregnation solution ratio upon the loaded amount of TBP and D2EHPA onto polyester sheet and charcoal (T: $25{ }^{\circ} \mathrm{C}$, time: $5 \mathrm{~h}$., ratio: 1/1 up to $1 / 10$ and Diluents: benzene. Conc.: 0.45 Molar).

\subsubsection{Effect of impregnation temperature}

The effect of temperature upon the impregnation process, series of impregnation experiments were carried out using temperatures ranged from 25 to $70{ }^{\circ} \mathrm{C}$. These experiments were performed under fixed conditions of $5 \mathrm{~h}$ impregnation time, $0.45 \mathrm{M}$ solvent concentrations, using benzene as diluent and $5 \mathrm{~g} / \mathrm{L}$. From the obtained results (Fig. 4), the impregnated amounts were decreased as the impregnation temperature increase. This phenomenon could be explained by the shape change of the inert support especially polyester sheet and the viscosity change of both TBP and D2EHPA solvents. Thus the preferred impregnation was room temperature $25^{\circ} \mathrm{C}$.

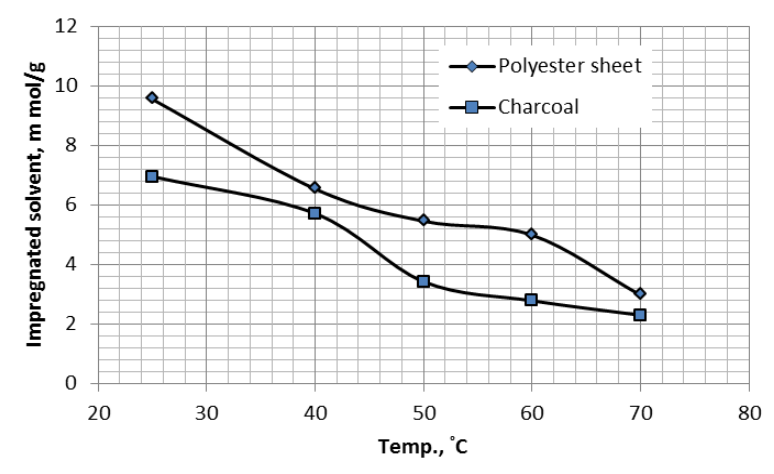

Fig. (4): Effect of impregnation temperature upon the impregnated Amount of TBP and D2EPHA onto polyester and charcoal (Conc.: $0.45 \mathrm{M}$; t: $5 \mathrm{~h}$., ratio: 5/l and Diluent: benzene).

\subsubsection{Effect of diluents type}

The impregnation solvents were diluted before its impregnation processes on polyester sheet and charcoal to reducing the solvent viscosity. By reducing the solvents viscosity the solvents extended on the supports surface and filling its interior pores. Different diluents were tested, namely; benzene, toluene, acetone, but-1-ol, and kerosene. The impregnation experiments were carried out under fixed conditions for both materials (polyester sheet and charcoal) of 0.45 $\mathrm{M}$ solvent concentrations, $5 / 1$ for mass/liquid ratio, impregnation time of $5 \mathrm{~h}$ for and the impregnation temperatures $25^{\circ} \mathrm{C}$. Fig 5 shows the obtained results which indicate that highest impregnation amounts were performed in benzene. In this case, benzene will be used as solvents diluent.

\subsubsection{Choice of optimum conditions for impregnation :}

As it was mentioned before, the impregnation process of TBP and D2EPHA on polyester sheet and charcoal is mainly due to a combination of pore filling as well as surface 
adsorption i.e. the extractants fill almost all porous system of polyester sheet and charcoal. Owing to the obtained results of the study of the relevant factors affecting polyester sheet and charcoal impregnation, we could safely choice the following preferred conditions; 0.45 $\mathrm{M}$ solvents concentration, $5 \mathrm{~h}$ impregnation time, $1 / 5$ mass/volume ratio, $25^{\circ} \mathrm{C}$ impregnation temperature and benzene as diluent.

\subsection{Results of equilibrium sorption studies}

In order to study the different factors affecting uranium sorption onto the prepared polyester sheet impregnated by TBP (PESIS) and charcoal impregnated by D2EHPA (CCIS), suitable amount $(1.5 \mathrm{~g})$ of each materials were treated with the two solvents under the above mentioned preferred impregnation conditions and used for the next studies. The studied factors are effect of contact time, effect of initial uranium concentrations, effect of solution $\mathrm{pH}$ and effect of adsorption temperature.

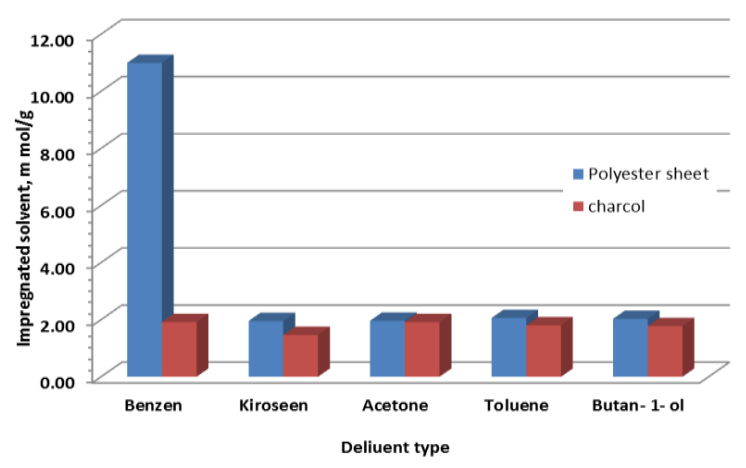

Fig. (5): Effect of diluents type upon the (TBP; D2EHPA) amounts onto the dry polyester sheet and charcoal (Conc.: $0.5 \mathrm{M}$; t: 5 h., ratio: $5 / 1$ and $\mathrm{T}: 25^{\circ} \mathrm{C}$ )

\subsubsection{Effect of contact time}

To determine the sorption equilibrium time of uranium by the prepared PESIS and CCIS, two series of sorption experiments were carried. The experiments were installed by contacting about $0.05 \mathrm{~g}$ from each material with the uranium stander solution having concentration of 160 and $220 \mathrm{mg} / \mathrm{L}$ for polyester sheet and charcoal respectively. The contact time was ranged from 15 to 300 minutes. The other factors were fixed at temperature of $25^{\circ} \mathrm{C}$, solution $\mathrm{pH}$ of 3.40 and $\mathrm{v} / \mathrm{m}$ ratio $5 \mathrm{~g} / \mathrm{L}$ The result was summarized in Fig. (6) which shows that the removal efficiency increasing by increasing the contact time from $15 \mathrm{~min}$ to about $50 \mathrm{~min}$. beyond the $3^{\text {th }}$ experiment $(30 \mathrm{~min})$ in case of polyester sheet and $4^{\text {th }}$ experiment $(60 \mathrm{~min}$.) in case of charcoal no significant improvement in the sorption efficiency were observed preferred. Accordingly, 30 and 60 min were chosen as contact time for sorption of uranium upon polyester sheet and charcoal respectively.

\subsubsection{Effect of $\mathrm{pH}$}

To determine the influence of $\mathrm{pH}$ value of the working solution upon uranium sorption onto the prepared PESIS and CCIS, two series of batch equilibrium experiments were achieved using different $\mathrm{pH}$ values ranging from 0 up to 7 . The experiments were performed under fixed of the other factors of initial uranium concentration of $100 \mathrm{mg} / \mathrm{l}$ for each PESIS and CCIS, at room temperature $(\approx$ $25^{\circ} \mathrm{C}$ ), contact time of 30 and $60 \mathrm{~min}$ for PESIS and CCIS respectively. To rich the required $\mathrm{pH}$ values different amount of $\mathrm{HNO}_{3}$ or $\mathrm{NaOH}$ were added. The aliquots (samples) of the uranium stander solution concentrations were fixed at $100 \mathrm{mg} / \mathrm{L}$ by adding specific quantities of uranium solution to compensate for the change occurred during $\mathrm{pH}$ adjustment. The results were plotted in Fig (7). The latter figure indicates that, the sorption efficiency decreasing significantly by increasing the solution $\mathrm{pH}$ beyond $\mathrm{pH}$ of 4 in both cases of PESIS and CCIS. This means that the adsorption of uranium is independent on the surface characteristics of the adsorbents at various $\mathrm{pH}$ values but may be correlated to the permanent surface negative charge of the prepared adsorbent and the chemical species forms of uranium in the aqueous phase. 


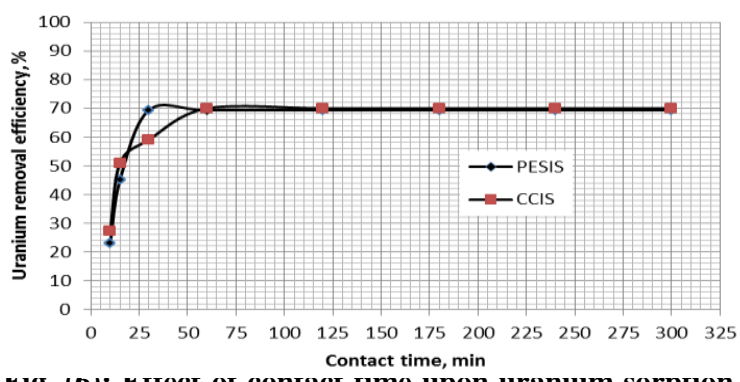

rig. (0): Entect or contaci ume upon uramum sorpuon efficiency onto PESIS $\left(\mathrm{T}=25^{\circ} \mathrm{C}\right.$; $\mathrm{pH}=3.08$; $\mathrm{U}$ conc. $=$ $220 \mathrm{ppm}$ ratio $5 \mathrm{~g} / \mathrm{l})$ and $\mathrm{CCIS}\left(\mathrm{T}=25^{\circ} \mathrm{C} ; \mathrm{pH}=3.40 ; \mathrm{U}\right.$ conc. $=160 \mathrm{ppm} ;$ ratio $=5 \mathrm{~g} / \mathrm{l})$.

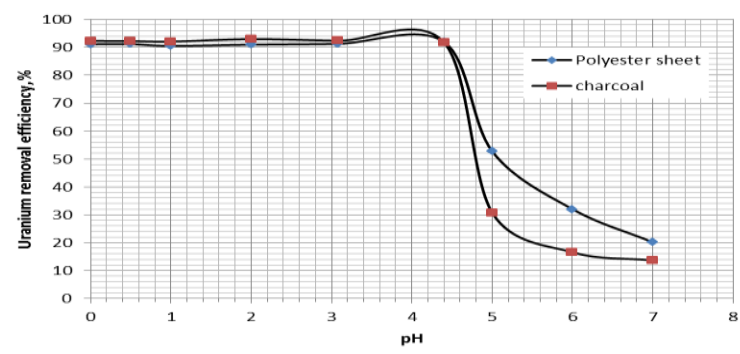

Fig. (7): Effect of solution pH upon uranium sorption efficiency onto PESIS and CCIS

$\left(\mathrm{T}=25^{\circ} \mathrm{C} ; \mathrm{U}\right.$ conc. $=100 \mathrm{mg} / \mathrm{L} ;$ ratio $\left.=5 \mathrm{~g} / \mathrm{l},\right)$.

The aqueous speciation distribution of uranium was calculated using Hydra-Medusa chemical equilibrium database and plotting software $[25,26]$ and obtained in Fig. 8. The results showed that the complexes of $\mathrm{UO}_{2} \mathrm{NO}_{3}{ }^{+}$ and $\mathrm{UO}_{2}{ }^{2+}$ were the main species at the $\mathrm{pH}$ range from 0 - 4 with mean total percent of about $35 \%$ and $65 \%$ respectively. At near neutral and alkaline $\mathrm{pH}$ conditions, Uhydroxide complexes start to dominate the aqueous phase. At $\mathrm{pH} 7$, the $\mathrm{UO}_{2}(\mathrm{OH})_{2} \cdot \mathrm{H}_{2} \mathrm{O}$ became the major species with about $100 \%$ of total concentration at $\mathrm{pH}$ range from 4.5 to 10.5 while at $\mathrm{pH} 12, \mathrm{UO}_{2}(\mathrm{OH})_{3}^{-}$became the main species within a total percent close to $70 \%$ of the total concentration. The formation of $\mathrm{UO}_{2}$ $(\mathrm{OH}){ }_{4}{ }^{2-}$ species started to grow after $\mathrm{pH} 10$.

According to the latter identification, the sorption mechanism of uranium on TBP impregnated polyester sheet was mainly solvation reaction. This conclusion was supported by the structural characteristics of TBP that have solvation properties, where the sorption mechanism could be suggested by succeeding equations [27]

$$
\begin{aligned}
& \mathrm{UO}_{2}^{2+}+2 \mathrm{NO}_{3}^{-}+2 \mathrm{TBP} \leftrightarrow \mathrm{UO}_{2}\left(\mathrm{NO}_{3}\right)_{2} \cdot 2 \mathrm{TBP} \\
& \mathrm{UO}_{2} \mathrm{NO}_{3}^{+}+\mathrm{NO}_{3}^{-}+2 \mathrm{TBP} \leftrightarrow \mathrm{UO}_{2}\left(\mathrm{NO}_{3}\right)_{2} \cdot 2 \mathrm{TBP}
\end{aligned}
$$

In case of D2EHPA impregnated charcoal was mainly pure ion surface complexation reaction. This conclusion was supported by the structural characteristics of D2EHPA that have ion exchange properties, where the adsorption mechanism could be proposed by following equations [28].

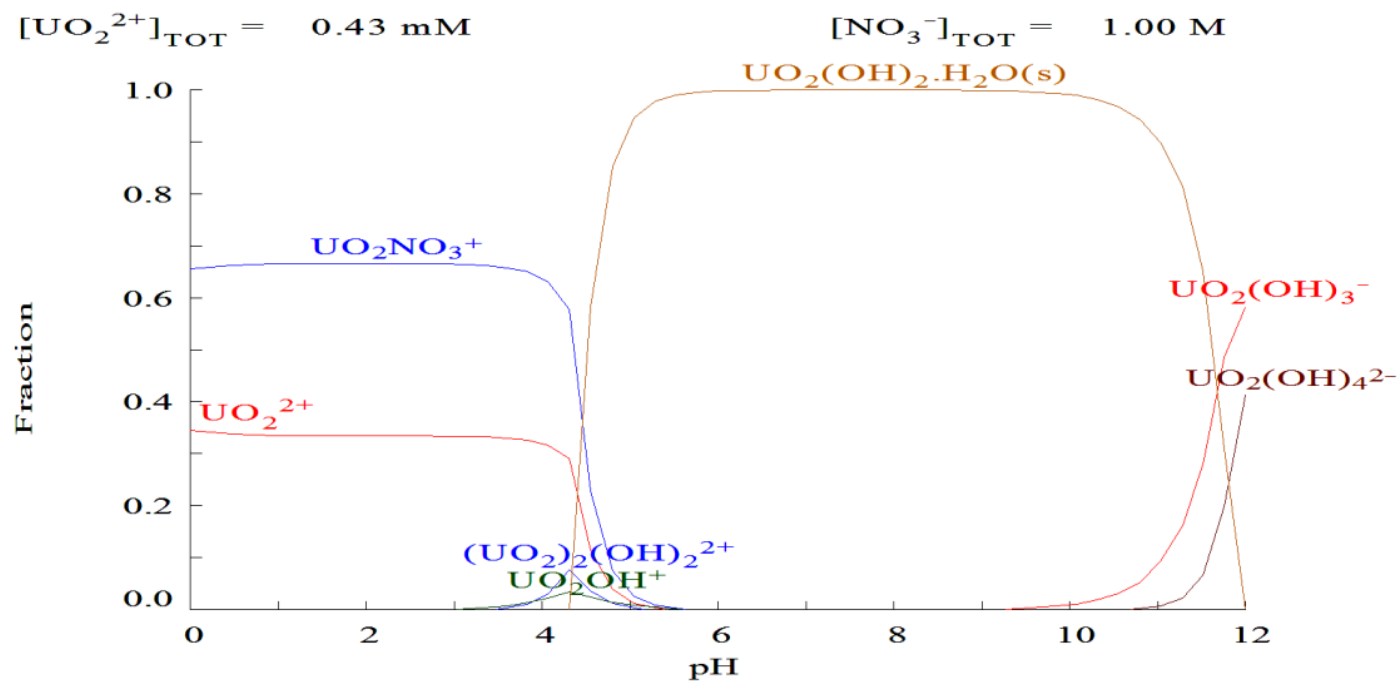

Fig. (8): Predicted aqueous speciation of $\mathrm{U}$ (VI) as a function of pH in $1 \mathrm{M} \mathrm{HNO}_{3}$ (pH of 0) using Hydra-Medusa program 
$2\left[\mathrm{UO}_{2}\left(\mathrm{NO}_{3}\right)\right]^{+}+(\mathrm{HD})_{2} \leftrightarrow 2\left[\mathrm{UO}_{2}\left(\mathrm{NO}_{3}\right) \mathrm{D}\right]+2(\mathrm{H})^{+}$

$2\left[\mathrm{UO}_{2}\left(\mathrm{NO}_{3}\right)\right]^{+}+(\mathrm{HD})_{2} \leftrightarrow 2\left[\mathrm{UO}_{2}\left(\mathrm{NO}_{3}\right) \mathrm{D}\right]+2(\mathrm{H})^{+}$

Where (HD) is D2EHPA.

\subsubsection{Effect of initial uranium concentration}

To examine the effect of initial uranium concentration on the sorption efficiency onto prepared PESIS and CCIS, two series of experiments were achieved by equilibrating $5 \mathrm{~g} / \mathrm{L}$ of nitrate solutions having different concentrations of the uranium ranged from 60 to $10000 \mathrm{mg} / \mathrm{L}$ for 30 and $60 \mathrm{~min}$ for PESIS and CCIS respectively at room temperature $\left(\approx 25{ }^{\circ} \mathrm{C}\right)$ and solution $\mathrm{pH}$ about 1. The result was obtained in Fig. 9 as a relation between uranium sorption efficiency and uranium ion concentration. From the obtained data, it was noticeable that uranium sorption efficiency decreased with increasing its initial concentration. The uranium adsorption capacity of prepared adsorbents materials are about 370 and $260 \mathrm{mg}$ U/g PESIS and CCIS respectively.

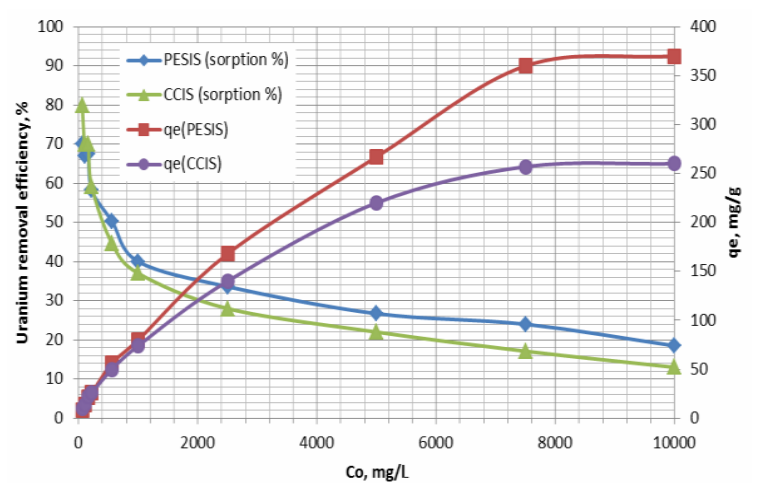

Fig. (9): Effect of uranium concentrations on sorption efficiency onto the prepared PESIS and CCIS

\subsubsection{Effect of sorption temperature}

To study the impact of temperature upon the uranium sorption onto the prepared PESIS and CCIS, two series of sorption experiments were performed using different temperatures ranging from 25 up to $70{ }^{\circ} \mathrm{C}$. In these experiments the other parameters were kept constant, at an initial uranium concentration of $100 \mathrm{mg} / \mathrm{L}$, solution $\mathrm{pH}$ value of 1 and a shaking time of 30 and $60 \mathrm{~min}$. for PESIS and CCIS respectively. From the obtained results plotted in Fig. (10), it is obviously that uranium sorption efficiency decreased with increasing the temperature. This may due to polyester sheet and charcoal surface change (become more flexible in case of polyester). For this reasons, room temperature $\left(\approx 25{ }^{\circ} \mathrm{C}\right)$ was chosen as the preferred temperature.

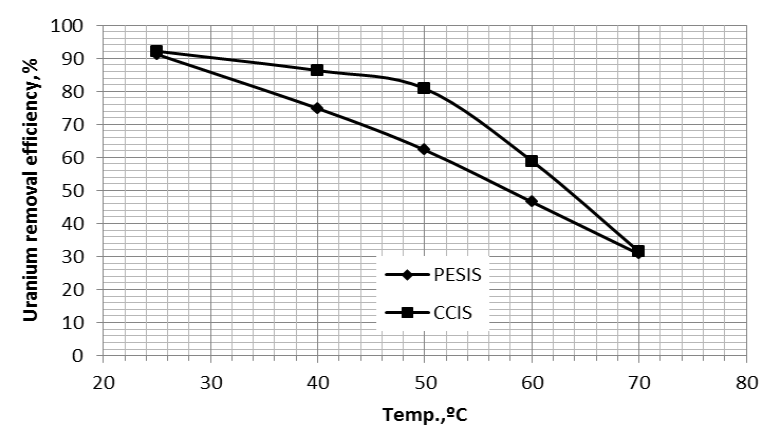

Fig. (10): Effect of solution temperature upon uranium sorption efficiency onto PESIS and CCIS $(\mathrm{pH}=1$; $\mathrm{U}$ conc. $100 \mathrm{mg} / \mathrm{L}$ and $\mathrm{t}=30$ and 60 min PESIS and CCIS respectively)

\subsubsection{Effect of the ratio of mass/volume ratio}

The effect of PESIS and CCIS mass / nitrate solution on the uranium $(100 \mathrm{mg} / \mathrm{L})$ sorption efficiency from nitrate solution was studied in the range from 1 to $10 \mathrm{~g} / \mathrm{L}$ at sorption time of 30 and $60 \mathrm{~min}$ PESIS and CCIS respectively, solution $\mathrm{pH}$ of 1 at room temperature $\left(\approx 25{ }^{\circ} \mathrm{C}\right)$ was explored. The experimental results were plotted in table Fig. 11 as a relation between uranium sorption efficiency and mass/volume ratio. As exposed in this figure the uranium adsorption efficiency percent increases from 40 and 45 to about 92 and 91 for PESIS and CCIS respectively by increasing the mass/volume ratio from 1 to 5 $\mathrm{g} / \mathrm{L}$. Beyond mass/volume of $5 \mathrm{~g} / \mathrm{L}$ there are no significant increasing in sorption efficiency. Therefore, PESIS and CCIS mass/ nitrate solution ratio were kept at $5 \mathrm{~g} / \mathrm{L}$ during all the experiments. 


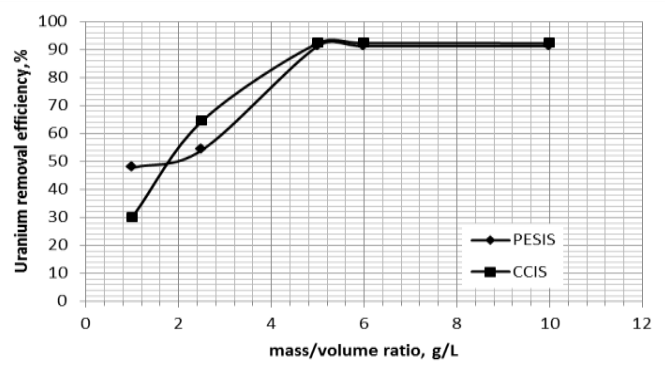

Fig. (11): Effect of solution $\mathrm{m} / \mathrm{v}$ ratio upon uranium sorption efficiency onto PESIS and CCIS

\subsubsection{Sorption isotherms}

The general sorption isotherms calculated from the variation of the initial concentration of uranium and calculating the remaining concentration. The distribution of the metal ion on PESIS and CCIS surface interfaces at equilibrium has been applied to different isotherms. The Langmuir isotherm was tested by plotting $\mathrm{C}_{\mathrm{e}} / \mathrm{q}_{\mathrm{e}}$ vs. $\mathrm{C}_{\mathrm{e}}$ where $\mathrm{C}_{\mathrm{e}}(\mathrm{g} / \mathrm{L})$ is the equilibrium concentration of the metal ion; $\mathrm{q}_{\mathrm{e}}$ ( $\mathrm{mg}$ metal $\left./ \mathrm{g}_{\text {sorbent }}\right)$ is the metal ion concentration in Fig. $(18,20)$ the obtained linear relation indicates that the extraction of U (VI) obeys Langmuir isotherm. Langmuir equation can be written as:

$$
C_{e} / q_{e}=1 / b Q^{0}+C_{e} / q^{o}
$$

Where $\mathrm{b}$ is Langmuir constant, $\mathrm{Q}^{\mathrm{o}}(\mathrm{mg}$ metal $/ \mathrm{g}$ sorbent) is the maximum amount of metal taken up. From the slope and the intercept of the linear relation obtained in Fig $(12,14) \mathrm{b}$ for $\mathrm{U}$ (VI) is 0.0006 and 0.0009 for polyester sheet impregnated with TBP and charcoal impregnated with D2EPHA. Although the Frundlich isotherm is usually regarded as empirical, this isotherm is applied by drawing a plot of $\log \mathrm{q}_{\mathrm{e}} \mathrm{vs} . \log \mathrm{C}_{\mathrm{e}}$. The logarithmic form of the equation is

\section{$\log q_{e}=\log K_{f}+1 / n \log C_{e}$}

Where $n, K_{f}$ are constants representing the adsorption capacity and intensity of adsorption respectively, they depend on the nature of the adsorbate, adsorbent, and temperature. The extraction of $U$ (VI) was found to follow the Frundlich isotherm due to the linear relation which obtained in Fig. $(13,15)$ from the slope and intercept of the plot, the Frundlich parameters are calculated $\mathrm{K}_{\mathrm{f}}$ found and $1 / \mathrm{n}$ to be $1.57,2.58 \mathrm{mg} / \mathrm{g}$ and 0.621 and 0.5235 for polyester sheet impregnated with TBP and charcoal impregnated with D2EPHA .

\section{SEM Characterization}

The surface of the impregnated supports was detected using Scanning Electron Microscope (SEM) in order to illustrate the change in the surface feature of the materials before and after impregnation and after uranium sorption. The obtained SEM was applied at different magnifications of at X100, 200 and 1000 for both adsorbents.

\section{Fourier Transform Infrared Spectrometer (FTIR)}

In order to support the pore filling phenomenon, the study polyester sheet and charcoal were subjected to qualitative IR spectroscopic characterization before and after its impregnation with the tri-N-butyl phosphate (TBP) and Di-2-ethylhexyl phosphoric acid (D2EHPA) solvent (Fig. 22 a, b, c) of the spectrum (a) before loading with TBP solvent, (b) after TBP loading and (c) after uranium adsorption. Shows the $\mathrm{P}=\mathrm{O}$ and $\mathrm{C}-\mathrm{O}-$ $\mathrm{P}$ stretching vibrations at 1227 and $1020 \mathrm{~cm}^{-1}$. The spectrum (c) (after loading with uranium) shows stretching band at 1099 and $1022 \mathrm{~cm}^{-1}$ which is characteristic formed complex between uranium and TBP on the polyester sheet.

Figure $23 \mathrm{a}, \mathrm{b}, \mathrm{c}$ refers to charcoal before impregnation (Fig. 23 a) by Di-2-ethylhexyl phosphoric acid (D2EHPA) and after impregnation (Fig. 23 b) and after uranium loading (Fig. 23 c). In figure 23 a, the characterized spectrum of charcoal at 1081 and $3451 \mathrm{~cm}^{-1}$ of $\mathrm{O}-\mathrm{H}$ and $\mathrm{C}=\mathrm{O}$ group respectively. After impregnation the characterized bands of $\mathrm{P}-\mathrm{O}-\mathrm{H}, \mathrm{P}-\mathrm{O}-\mathrm{C}$ and $\mathrm{P}=\mathrm{O}$ at 885,1032 and 1222 $\mathrm{cm}^{-1}$ of D2EHPA. After loading of uranium the D2EHPA characterized bands were shifted to 930,1034 and $1202 \mathrm{~cm}^{-1}$. These refer to the formation of complex between uranium and D2EHPA on the charcoal surface. 
Table (2): Langmuir and Freundlich parameters for uranium sorption onto PESIS and CCIS

\begin{tabular}{|c|c|c|c|c|c|c|}
\hline \multirow{2}{*}{ TBP } & \multicolumn{3}{|c|}{ Frundlich isotherm model } & \multicolumn{3}{c|}{ Langmuir isotherm model } \\
\cline { 2 - 7 } & $\mathbf{1} / \mathbf{n}$ & $\mathrm{Kf}(\mathrm{mg} / \mathrm{Kg})$ & $\mathbf{R}^{2}$ & $\mathbf{Q m}$ & $\mathbf{b}(\mathrm{L} / \mathbf{m g})$ & $\mathbf{R}^{2}$ \\
\hline D2EHPA & $\mathbf{0 . 6 2 1}$ & 1.57 & 0.9955 & 434 & 0.0006 & 0.947 \\
\hline
\end{tabular}
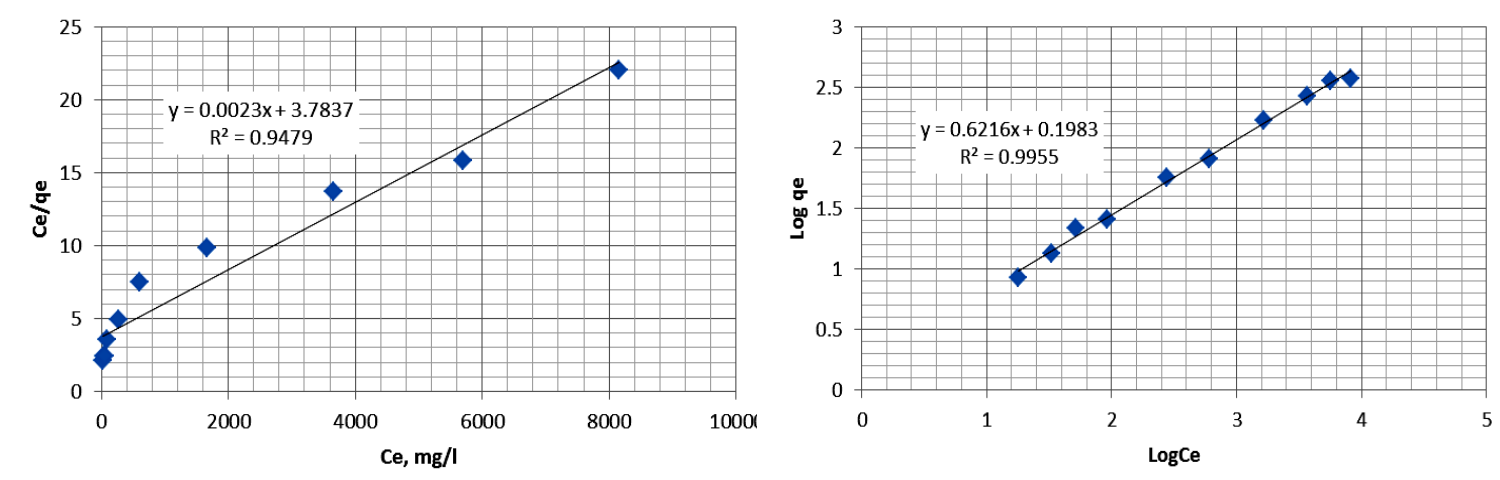

Fig (12, 13): Langmuir and Freundlich sorption isotherms for uranium onto the prepared PESIS
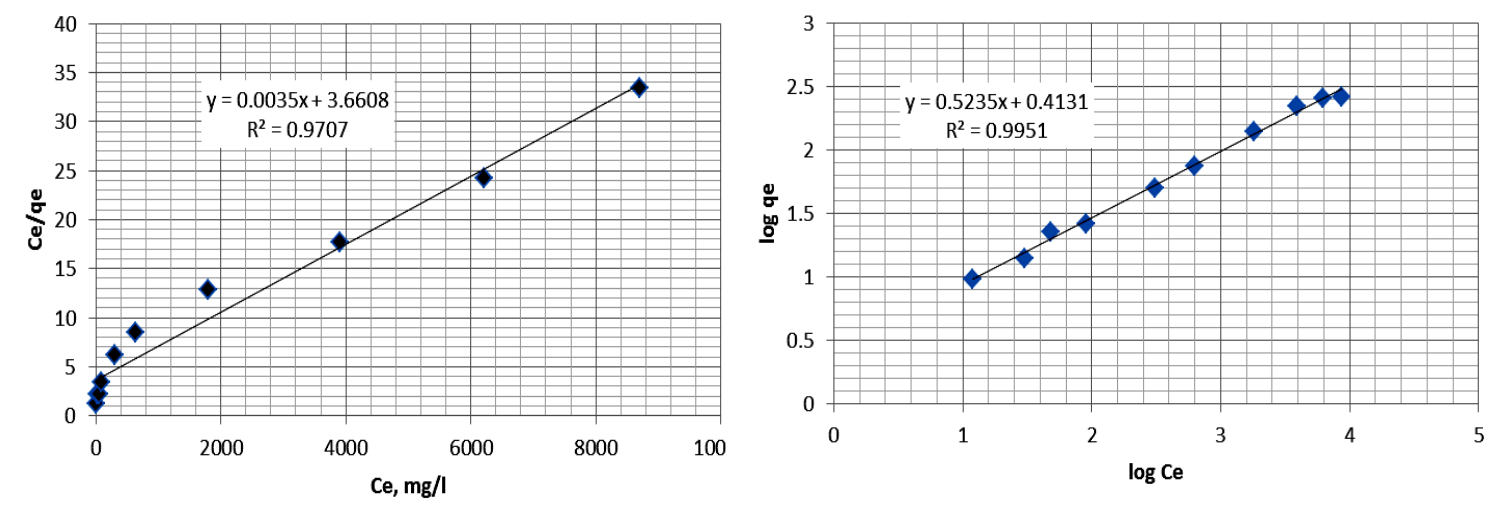

Fig $(14,15)$ : Langmuir and Freundlich sorption isotherms for uranium onto the prepared CCIS
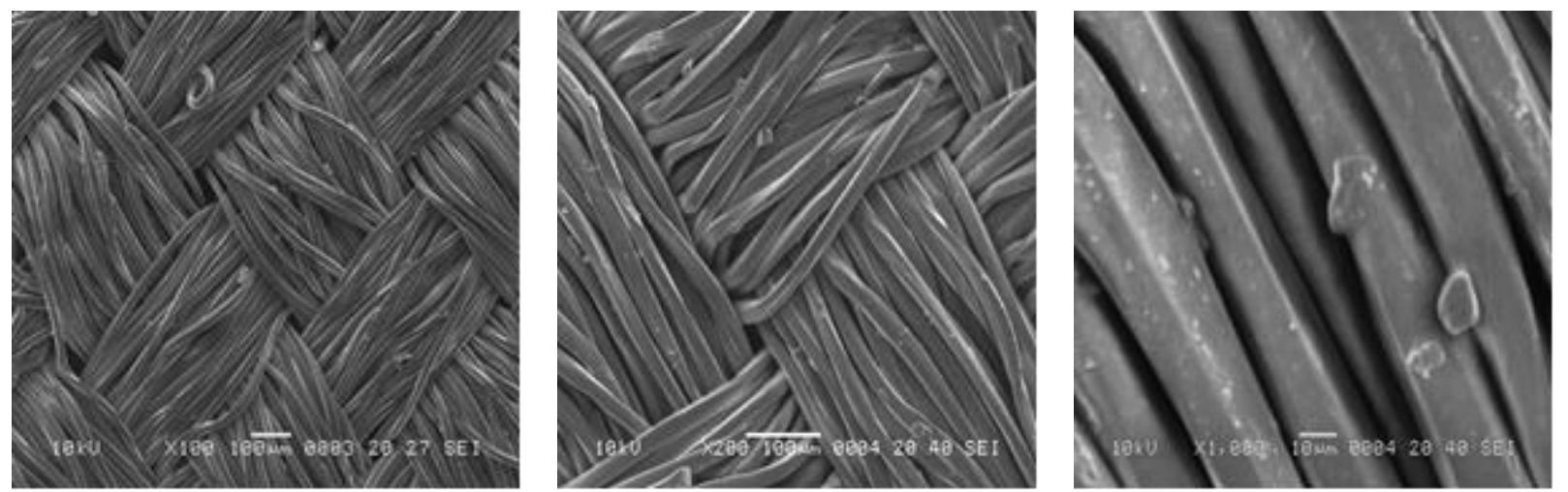

Fig. (16): SEM photographs of the polyester sheet surface before impregnation with TBP 

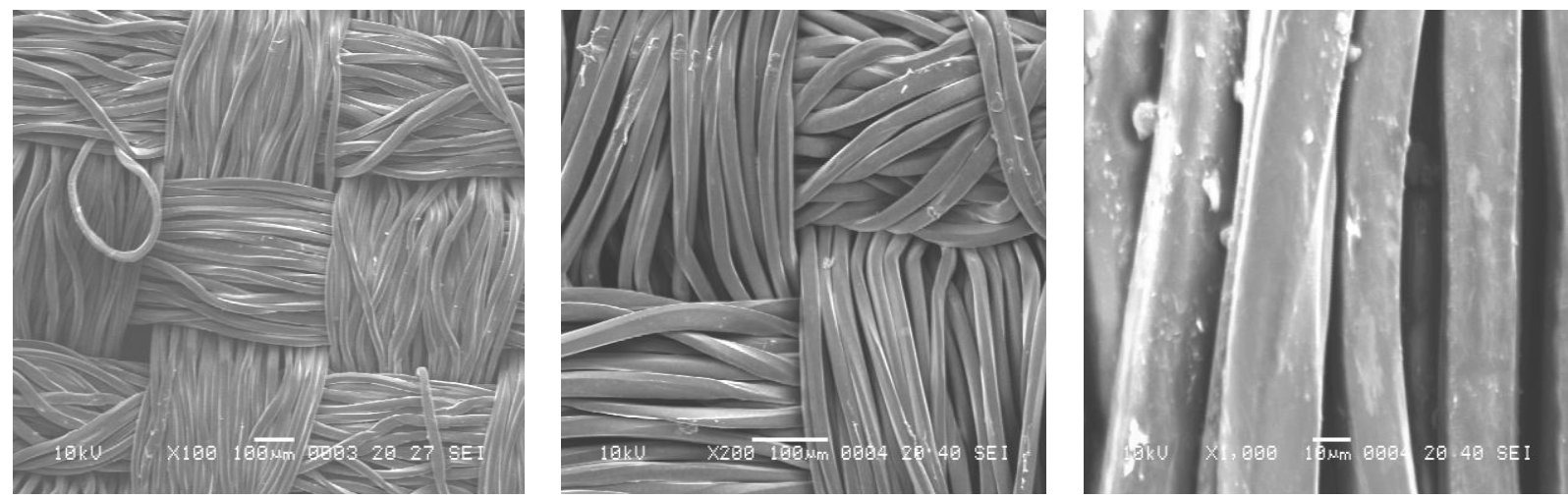

Fig. (17): SEM photographs of the polyester sheet surface after impregnation with TBP
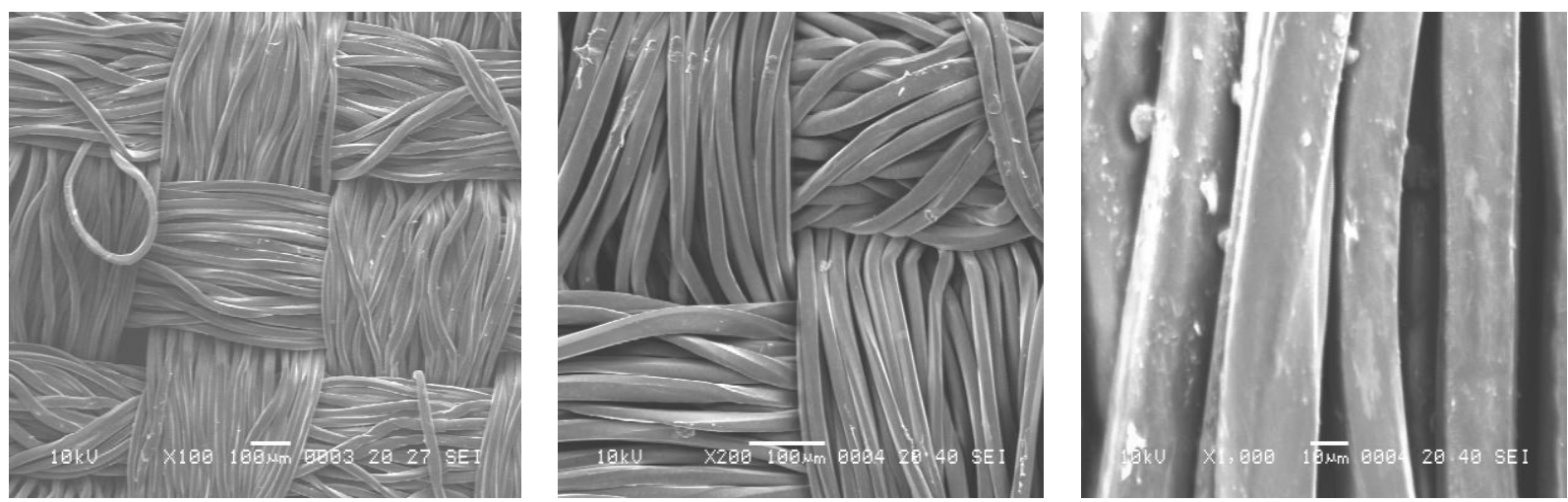

Fig. (18): SEM photographs of the polyester sheet surface after impregnation with TBP after uranium leaded
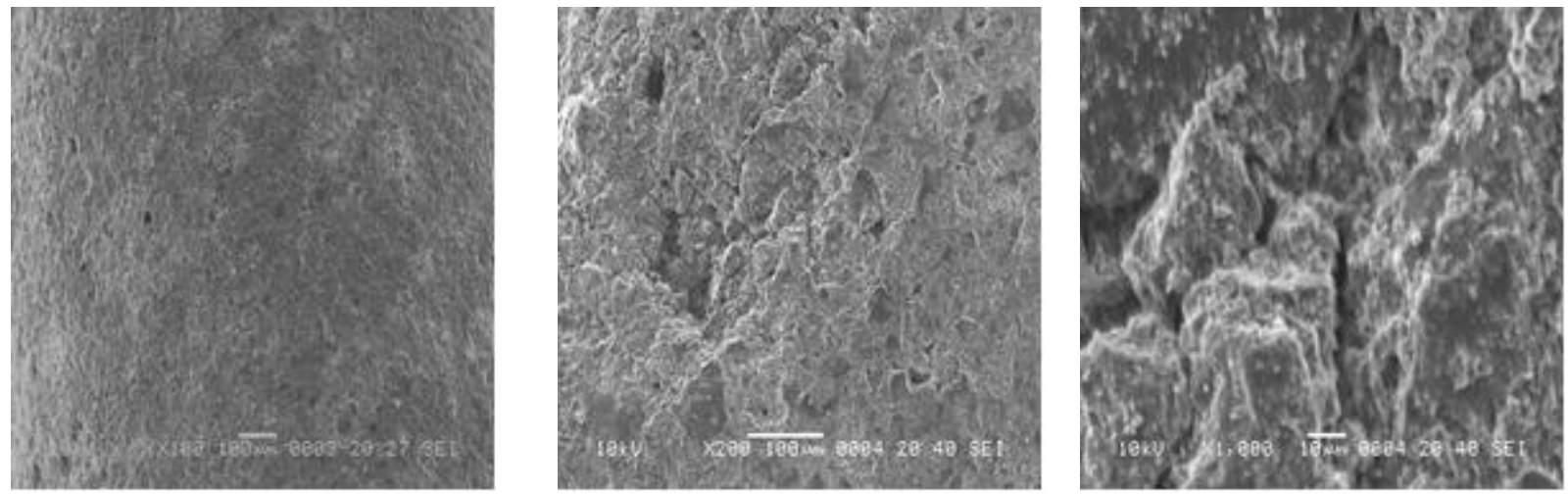

Fig. (19): SEM photographs of the charcoal sheet surface before impregnation with D2EHPA
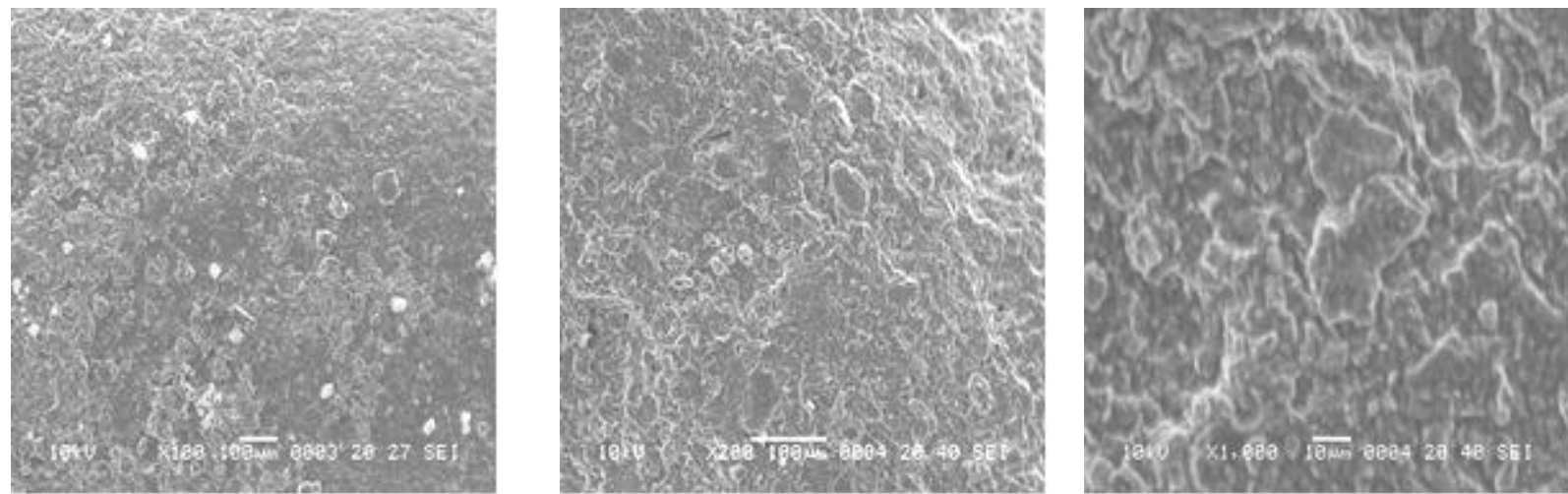

Fig. (20): SEM photographs of the charcoal sheet surface after impregnation with D2EHPA 

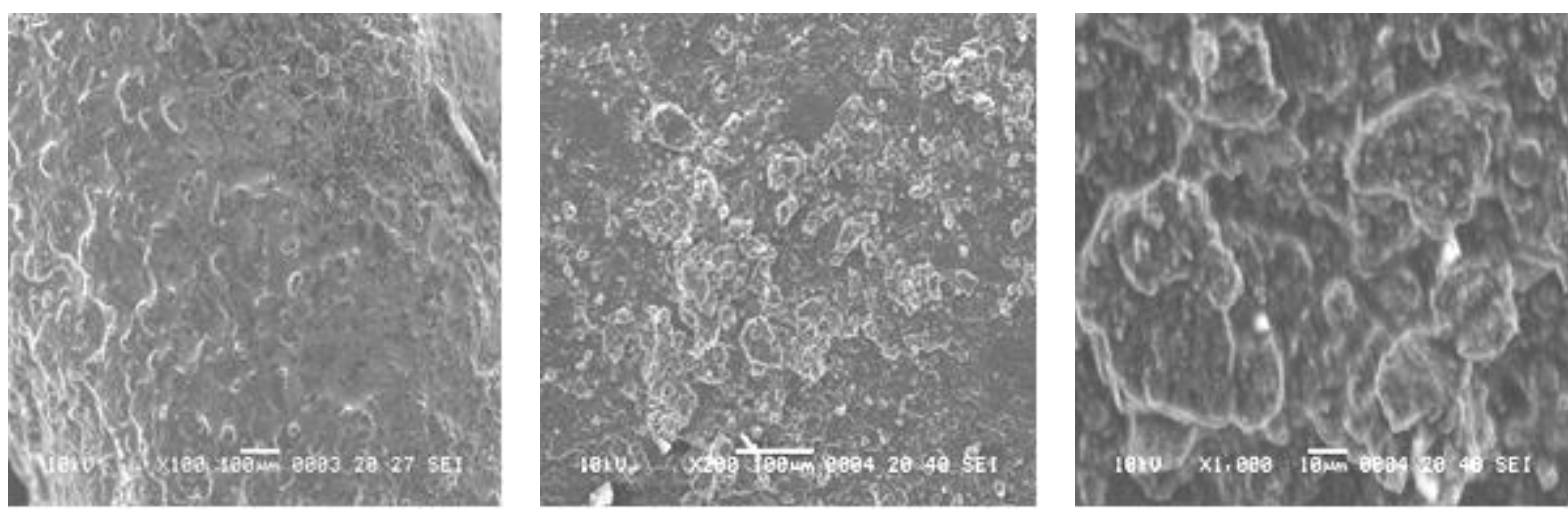

Fig. (21): SEM photographs of the charcoal sheet surface after impregnation with D2EHPA after loaded
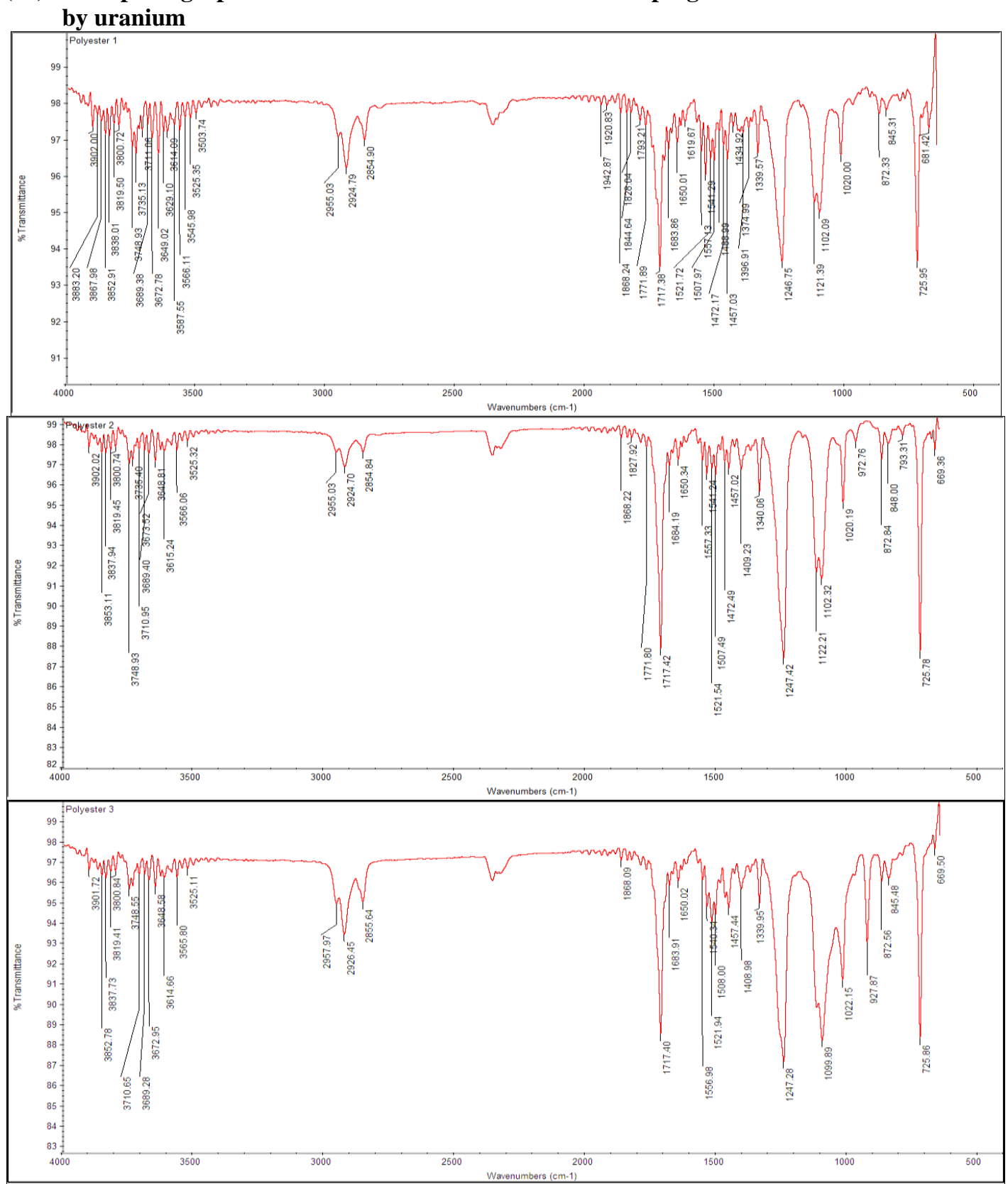

Figure (22): IR photographs of the polyester sheet surface before impregnation, after impregnation by TBP and after uranium loading 


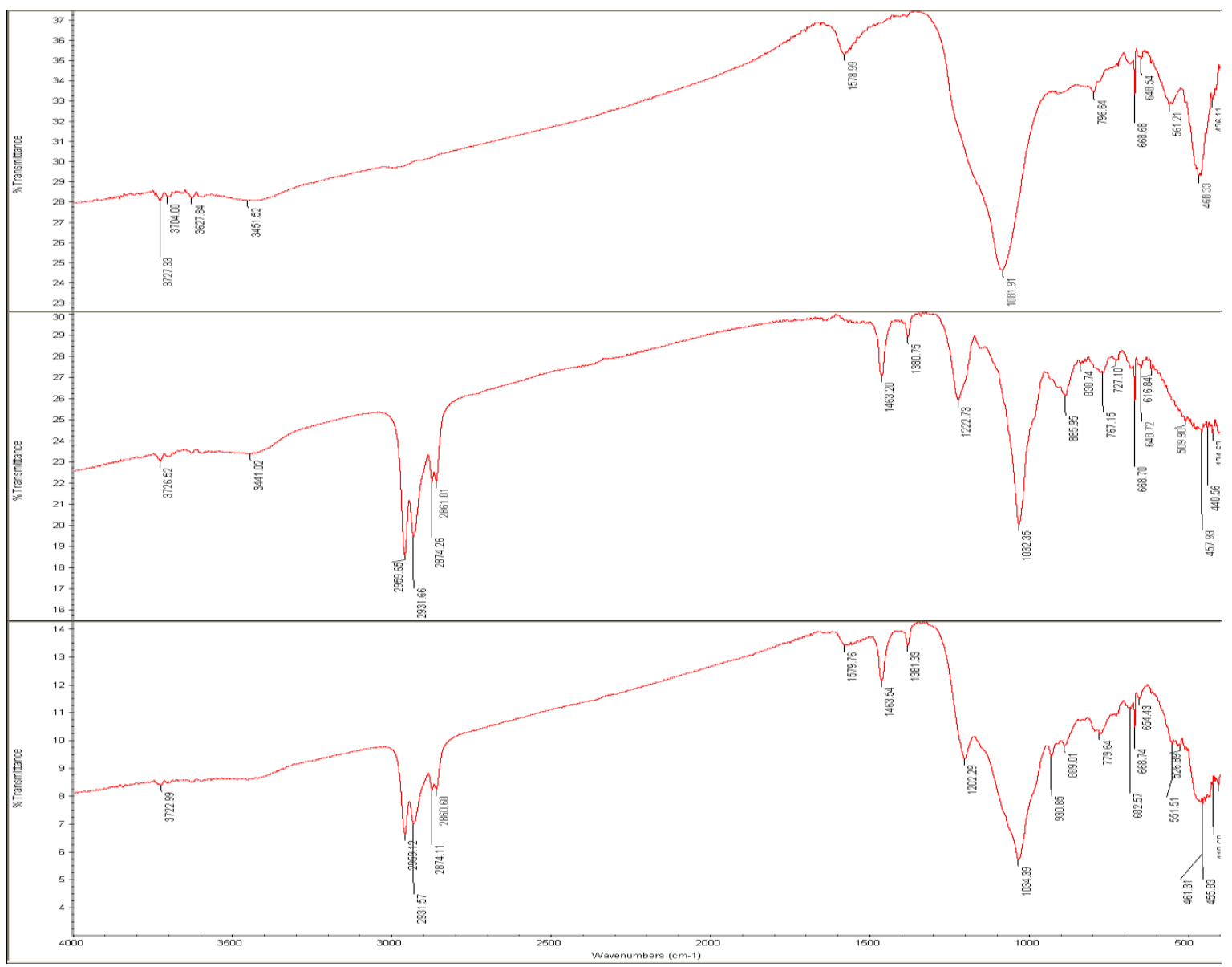

Figure (23 a, b, c): IR photographs of the charcoal surface before impregnation, after impregnation by D2EHPA and after uranium loading.

\section{Elution Studies}

In order to achieve maximum uranium elution form the prepared adsorbents, number of elution excrements were carried out to elute the uranium ion from the impregnated polyester sheet and charcoal. Uranium loaded materials were subjected to elution experiments by contacting fixed amount $(0.1 \mathrm{~g})$ with different eluent solutions $(10 \mathrm{ml})$ of $\mathrm{H}_{2} \mathrm{O}, 1 \mathrm{M}$ $\mathrm{NaCl}+0.1 \mathrm{M} \mathrm{H}_{2} \mathrm{SO}_{4}, \mathrm{HNO}_{3}$, Tartaric acid, citric acid and $\mathrm{Na}_{2} \mathrm{CO}_{3}$ with different concentrations to obtain the maximum elution efficiency.

From the obtained results plotted in Fig. 24 and Fig. 25 showed that $1 \mathrm{M} \mathrm{Na}_{2} \mathrm{CO}_{3}$ and $0.1 \mathrm{M}$ $\mathrm{HNO}_{3}$ elute about 96 and $95 \%$ from the loaded uranium on prepared polyester sheet and charcoal.
Case study (Uranium removal from the raffinate solution)

\section{- Uranium adsorption}

As previously stated, the prepared adsorbents has uranium adsorption capacity (about $434 \mathrm{mg} \mathrm{U} / \mathrm{g}$ polyester sheet impregnated by TBP and about $285 \mathrm{mg}$ U/g charcoal impregnated by D2EHPA ). In the present work, the study of uranium removal from Nuclear Material Authority, Egypt, liquid raffinate solution was carried out. Batch experiment was performed by contacting different amounts $(0.1 \mathrm{~g})$ of prepared polyester sheet impregnated by TBP and charcoal impregnated by D2EHPA. 


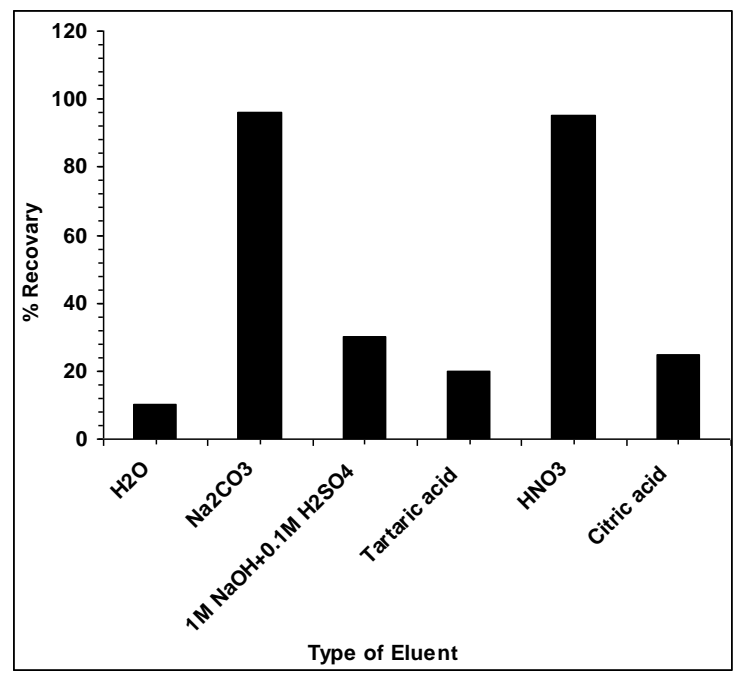

Fig. (24): Effect of different eluent reagents on uranium elution efficiency from polyester impregnated by TBP.

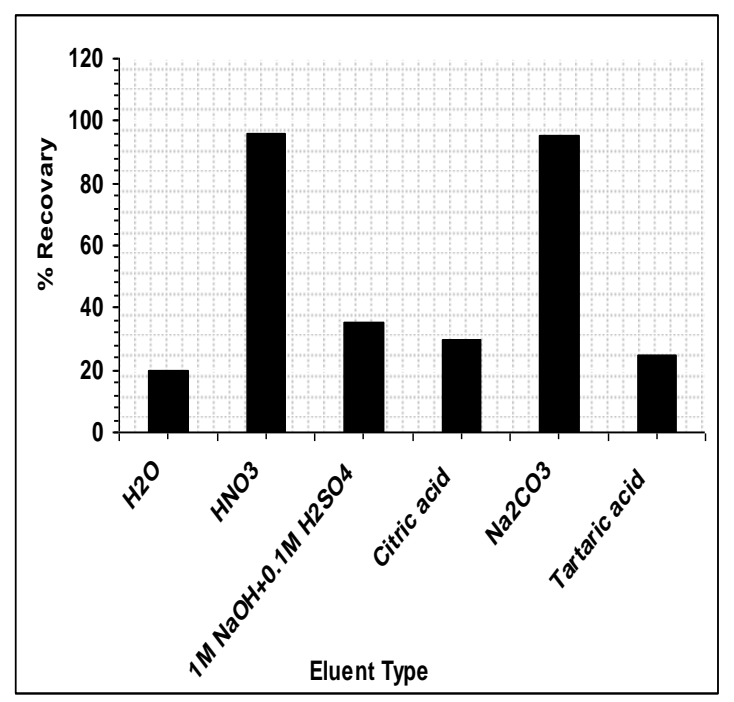

Fig (25): Effect of different eluent reagents on uranium elution efficiency from charcoal impregnated by D2EHPA.
Each $0.1 \mathrm{~g}$ were contacted with two different volumes $(200 \mathrm{~mL})$ of raffinate for 90 min. the calculated loaded uranium content from its analysis in the effluent samples were illustrated in table 3.

\section{- Uranium elution}

Using the $1 \mathrm{M} \mathrm{Na} \mathrm{CO}_{3}$ and $0.1 \mathrm{M} \mathrm{HNO}_{3}$ eluent reagents about 94 and $93 \%$ from the loaded uranium on polyester sheet and charcoal were eluted. By calculating of the eluted uranium amounts revealed that 434 and 285.70 mg uranium/g polyester sheet and charcoal were eluted.

\section{CONCLUSION}

The results of this indicate that the polyester and charcoal could by converted into efficient adsorbent materials for uranium removal from aqueous solution by impregnate those materials by different solvents. The maximum adsorption capacity of the prepared impregnated materials are about than 434 and $285 \mathrm{mg} / \mathrm{g}$. Adsorption isotherms indicate the uranium adsorption onto the prepared impregnated materials are a monolayer adsorption process. Resulting test on the uranium ion removal from raffinate solution could serve as potential applicability of these adsorbents in industrial wastewater treatment.

Table 3: Results of uranium removal from real raffinate solution by the prepared materials

\begin{tabular}{|c|c|c|c|c|c|c|c|}
\hline $\begin{array}{l}\text { Adsorbent } \\
\text { material }\end{array}$ & $\begin{array}{c}\text { Raffinate } \\
\text { solution, } \\
\text { ml }\end{array}$ & $\begin{array}{l}\text { uranium } \\
\text { amount, } \\
\text { g }\end{array}$ & $\begin{array}{l}\text { Adsorbent } \\
\text { amount, g }\end{array}$ & $\begin{array}{l}\text { Adsorbed } \\
\text { uranium } \\
\text { amount, g }\end{array}$ & $\begin{array}{l}\text { Theoretical } \\
\text { adsorbed } \\
\text { amount, g/g }\end{array}$ & $\begin{array}{c}\text { Different } \\
\text { between } \\
\text { theoretical } \\
\text { and practical } \\
\text { capacities, } \\
\%\end{array}$ & cause \\
\hline Polyester & \multirow[t]{2}{*}{200} & \multirow[t]{2}{*}{0.2} & \multirow[t]{2}{*}{0.1} & 0.184 & 0.434 & 42.3 & \multirow{2}{*}{$\begin{array}{c}\text { Iron } \\
\text { competition }\end{array}$} \\
\hline Charcoal & & & & 0.170 & 0.285 & 59.6 & \\
\hline
\end{tabular}




\section{ACKNOWLEDGEMENT}

The author would like to express his sincere thanks to Prof. Dr. A. E. M. Hussein for deeply useful scientific discussions during performing this paper.

\section{REFERENCE}

1- S. Chakraborty, F. Favre, D. Banerjee, A.C. Scheinost, M. Mullet, J.J. Ehrhardt, J. Brendle, L.C. Vidal, L. Charlet, U(VI) Sorption and Reduction by Fe(II) Sorbed on Montmorillonite, Environ. Sci. Technol. 44(2010) 3779-3785.

2- M. Majdan, S. Pikus, A. Gajowiak, D. Sternik, E. Zięba, Uranium sorption on bentonite modified by octadecyltrimethylammonium bromide, $J$. Hazard. Mater.184(2010) 662-670.

3- Y. Sun Y, C. Ding, W. Cheng, X. Wang, Simultaneous adsorption and reduction of $\mathrm{U}(\mathrm{VI})$ on reduced graphene oxide-supported nanoscale zerovalent iron, J. Hazard. Mater. 280(2014) 399-408.

4- Kawabata Y, Aparin V, Nagai M, Yamamoto M, Shiraishi K, Katayama Y (2008) Uranium and thorium isotopes from Kazakhstan.J Radioanal Nucl Chem 278(2):459-462.

5- Chellam S, Clifford DA (2002) Physicalchemical treatment of groundwater contaminated by leachate from surface disposal of uranium tailings. J Environ Eng 128:942-952.

6- Phillips DH, Gu B, Watson DB, Parmele CS (2008) Uranium removal from contaminated groundwater by synthetic resins. Water Res 42:260-268

7- Xie S, Yang J, Chen C, Zhang X, Wang Q, Zhang C (2008) Study on biosorption kinetics and thermodynamics of uranium by Citrobacter freudii. $\mathbf{J}$ Environ Radioact 99:126-133.

8- Rahman ROA, Ibrahium HA, Hung YT (2011) Liquid radioactive wastes treatment: a review. Water 3:551-565.

9- Camacho LM, Deng S, Parra RR (2010) Uranium removal from groundwater by naturalclinoptilolite zeolite: effects of $\mathrm{pH}$ and initial feed concentration. J Hazard Mater $175: 1-3$
10- M.B. Mansur, S.D. Ferreira Rocha, F.S. Magalhaes, J.S. Benedetto, Selectiveextraction of zinc(II) over iron(II) from spent hydrochloric acid pickling effluents by liquid-liquid extraction, J. Hazard Mater. 150 (2008) 669-678.

11- M. Maradi, Y. Yamini, A. Esrafili, S. Seidi, Application of surfactant assisted dispersive liquid-liquid microextraction for sample preparation of chlorophenols in water samples, Talanta 82 (2010) 1864-1869.

12- J.S. Chiang, S.D. Huang, Simultaneous derivatization and extraction of anilines in waste water with dispersive liquid-liquid microextraction followed by gas chromatography-mass spectrometric detection, Talanta 75 (2008) 70-75.

13- R.F. Li, C.X. Liu, H.G. Zhao, S.H. He, Z. Li, Q.N. Li, L. Zhang, Di-1-methyl heptyl methylphosphonate (DMHMP): A promising extractant in Th-based fuel reprocessing, Sep. Purif. Technol. 173 (2017) 105-112.

14- M.L. Tan, C. Huang, S.D Ding, F. Li, Q.N. Li, L. Zhang, C.X. Liu, S.M. Li, Highly efficient extraction separation of uranium(VI) and thorium(IV) from nitric acid solution with di(1-methyl-heptyl) methyl phosphonate, Sep. Purif. Technol. 146 (2015) 192-198.

15- T.P. Rao, P. Metilda, J.M. Gladis, Preconcentration techniques for uranium(VI) and thorium(IV) prior to analytical determination-an overview, Talanta 68 (2006) 1047-1064.

16- E.P. Horwitz, D.R. Mcallister, A.H. Bond, R.E. Barans, Novel Extraction of Chromatographic Resins Based on Tetraalkyldiglycolamides: Characterization and Potential Applications, Solvent Extr. Ion. Exc. 23 (2005) 319-344.

17- V.N. Epov, K. Benkhedda, R.J. Cornett, R.D. Evans, Rapid determination of plutonium in urine using flow injection on-line preconcentration and inductively coupled plasma mass spectrometry, J. Anal. At Spectrom 20 (2005) 424-430.

18- Metilda P, Sanghamitra K, Gladis JM, Naidu GRK, Rao TP (2005) Amberlite XAD-4 functionalized with succinic acid for the solid phase extractive preconcentration and separation of uranium(VI). Talanta 65:192200 
19- Donat R, C1lg1 GK, Aytas S, Cetisl H (2009) Thermodynamics parameters and sorption of U(VI) on ACSD. Radioanal Nucl Chem 279:271 280

20- Merritt RC (1971) The extractive metallurgy of uranium. Colorado School of Mines Research Institute, Chicago.

21- Marczenko Z, Balcerzak M (2000) Separation, preconcentration and spectrophotometry in inorganic analysis. Elsevier Science B.V., Amsterdam, p 521.

22- Rohwer H, Rheeder N, Hosten E (1997) Interactions of uranium and thorium with arsenazoIII in an aqueous medium. Anal Chim Acta 341(2):263-268.

23- Davies W, Gray W (1964) A rapid and specific volumetric method for the precise determination of uranium using ferrous sulfate as a reductant', Talanta 11:12031211.

24- Mathew KJ, Mason B, Morales ME, Narayann UI (2009) Uranium assay determination using Davies and Gray titration: an overview and implementation of GUM uncertainty evaluation.Radio Anal Nucl Chem 282:939-944.

25- Puigdomenech I. HYDRA (hydrochemical equilibrium-constant database) and MEDUSA (make equilibrium diagrams using sophisticated algorithms) programs, Royal Institute of Technology, Sweden. https://www.kth.se/en/che/medusa/downloads $-1.386254$

26- Y.M.Khawassek, A.M.Masoud, M.H.Taha and A.E.M. Hussein (2018) Kinetics and thermodynamics of uranium ion adsorption from waste solution using Amberjet $1200 \mathrm{H}$ as cation exchanger. J Radioanal Nucl Chem (2018). https://doi.org/10.1007/s10967-0175692-1

27- Jamal Stas, Ajaj Dahdouh and habib Shlewit (2005) "Extraction of uranium (VI) from nitric acid And nitrate solutions By tributylphosphate/kerosene" periodica polytechnica ser. chem. eng. vol. 49, no. 1, pp. 3-18.

28- HAIDUC, I., M. CURTUI, I. HAIDUC (1986) "Solvent extraction of uranium(vi) with di-2-ethylhexyldithiophosphoric acid from aqueous nitrate, chloride, sulfate and phosphate media" Journal of Radio analytical and Nuclear Chemistry, Articles, V. 99, No. 2, 257-263.
29- Merritt, R. C., The Extractive Metallurgy of Uranium, 1971, Colorado School of Mines Research Institute, USAEC, Johnson, Boulder, Co, 1971, p. 195.

30- O* lmez, S., and Eral, M., J. Biol. Trace Element Res., 1994, 43-45, 731
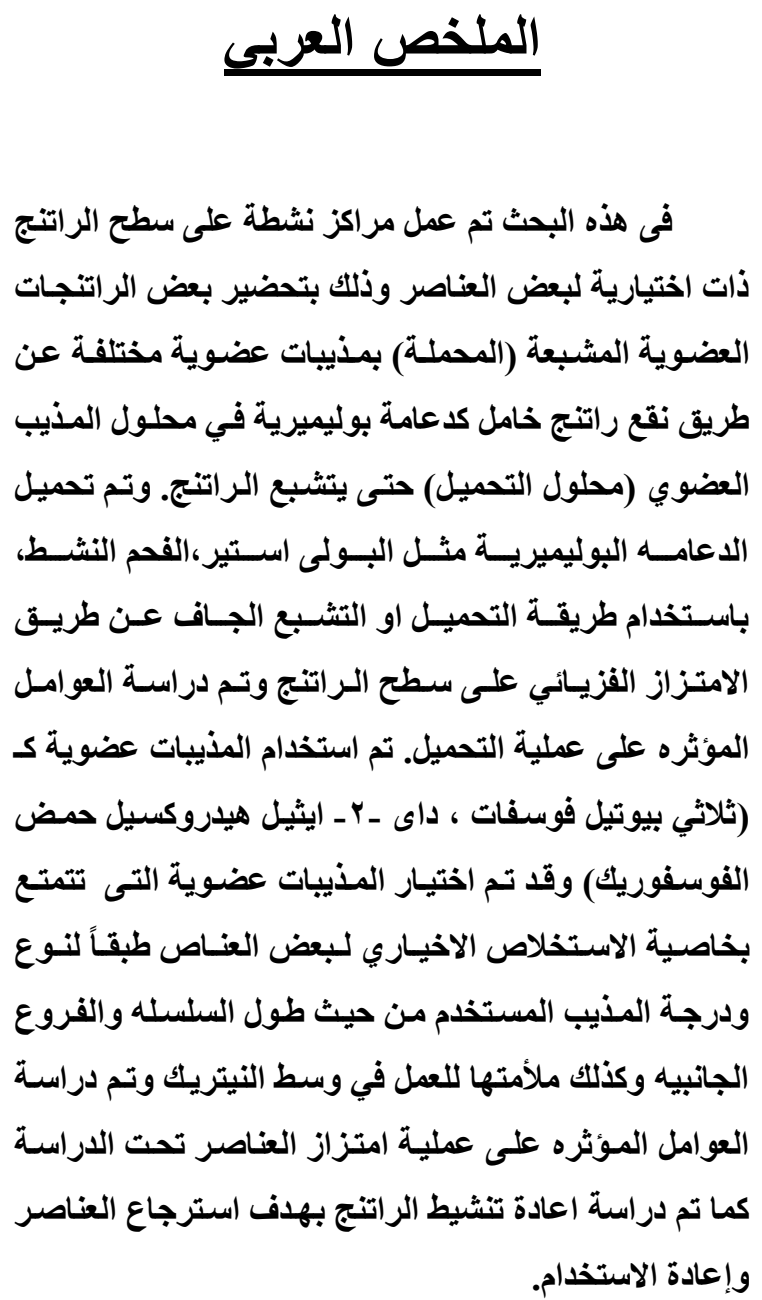